\title{
PENDIDIKAN KESEHATAN PERTOLONGAN PERTAMA PADA KECELAKAAN (FIRST AID) PADA SISWA/SISWA SMA KAMPAR RIAU
}

\author{
Putri Wulandini $\mathbf{S}^{1)}$, Andalia Roza ${ }^{2)}$, Kiki Parmanda ${ }^{3)}$ \\ ${ }^{1-3}$ Universitas Abdurrab \\ Surel: nsputriwulandiniskepmkes@gmail.com
}

\begin{abstract}
First Aid is a temporary relief and care effort against accident victims before getting more complete help from doctors or paramedics. This means that the help is not a perfect treatment or treatment, but only a temporary relief by the FIRST AID officer (medical officer or lay person) who first sees the victim. First Aid Purpose: 1 Prevent death, 2. Prevent more severe disability 3. Prevent infections, 4. Reduce pain and fear Correct FIRST AID action will reduce defects or suffering and even save the victim from death, but if FIRST AID action is done bad it can worsen due to accident and even kill the victim. In everyday life there is often an accident that befell someone or a group of people. Accidents can happen anywhere, at home, road, workplace or anywhere else. To anticipate the problem then the government launched the school health effort movement (UKS) which there is health education, health services and a healthy school environment. The purpose of this dedication is to train the students to be the first helpers to be able to perform first aid measures if necessary.
\end{abstract}

Keywords: health education, first aid in accident

\begin{abstract}
ABSTRAK
First Aid adalah upaya pertolongan dan perawatan sementara terhadap korban kecelakaan sebelum mendapat pertolongan yang lebih sempurna dari dokter atau paramedik. Berarti pertolongan tersebut bukan sebagai pengobatan atau penanganan yang sempurna, tetapi hanyalah berupa pertolongan sementara yang dilakukan oleh petugas First Aid (petugas medik atau orang awam) yang pertama melihat korban. Tujuan First Aid: Mencegah kematian, Mencegah cacat yang lebih berat, Mencegah infeksi, Mengurangi rasa sakit dan rasa takut. Tindakan First Aid yang dilakukan dengan benar akan mengurangi cacat atau penderitaan dan bahkan menyelamatkan korban dari kematian, tetapi bila tindakan First Aid dilakukan tidak baik malah bisa memperburuk akibat kecelakaan bahkan membunuh korban. Dalam kehidupan sehari-hari sering terjadi kecelakaan yang menimpa seseorang atau sekelompok orang. Kecelakaan bisa terjadi dimana saja, di rumah, jalan, tempat kerja atau ditempat lainnya. Untuk mengantisipasi masalah itu maka pemerintah mencanangkan gerakan usaha kesehatan sekolah (UKS) yang mana terdapat pendidikan kesehatan, pelayanan kesehatan dan lingkungan sekolah yang sehat. Tujuan pengabdian ini yakni untuk melatih siswanya menjadi tenaga penolong pertama agar mampu melakukan tindakan pertolongan pertama apabila diperlukan.

Kata Kunci: pendidikan kesehatan, pertolongan pertama pada kecelakaan
\end{abstract}




\section{PENDAHULUAN}

P3K (First Aid) adalah upaya pertolongan dan perawatan sementara terhadap korban kecelakaan sebelum mendapat pertolongan yang lebih sempurna dari dokter atau paramedik. Berarti pertolongan tersebut bukan sebagai pengobatan atau penanganan yang sempurna, tetapi hanyalah berupa pertolongan sementara yang dilakukan oleh petugas P3K (petugas medik atau orang awam) yang pertama melihat korban.

Tindakan P3K yang dilakukan dengan benar akan mengurangi cacat atau penderitaan dan bahkan menyelamatkan korban dari kematian, tetapi bila tindakan P3K dilakukan tidak baik malah bisa memperburuk akibat kecelakaan bahkan membunuh korban.

Dalam kehidupan sehari-hari sering terjadi kecelakaan yang menimpa seseorang atau sekelompok orang. Kecelakaan bisa terjadi dimana saja, di rumah, jalan, tempat kerja atau ditempat lainnya. Umumnya kecelakaan terjadi tanpa diduga sebelumnya dan akibat yang ditimbulkannya bervariasi, bisa berupa cedera ringan, sedang, berat bahkan sampai meninggal dunia.

Berdasarkan jumlah korban, kecelakaan bisa terjadi dengan satu korban, banyak korban (musibah) atau sangat banyak korban (bencana). Ada beberapa faktor yang mempengaruhi nasib atau akhir derita korban, antara lain: Keparahan cedera, waktu antara kejadian sampai pelayanan P3K, sarana/ fasilitas P3K, keterampilan petugas P3K, jarak tempuh ke rumah sakit, ketersediaan alat transportasi ke rumah sakit dan adanya komunikasi ke rumah sakit tujuan. Apabila semua faktor ini berfungsi dan tersedia dengan baik maka dampak dari cedera bias diperkecil dan kerugian yang lebih besar bias dihindari.

Didalam kelompok masyarakat, khususnya di sekolah mutlak adanya tenaga P3K yang terampil terutama di lokasi kerja/ sekolah yang banyak menggunakan mesin dan teknologi canggih, bahan beracun. Bahkan ketidakdisiplinan siswa juga bisa menyebabkan cedera. Untuk mengantisipasi masalah itu maka pemerintah mencanangkan gerakan usaha kesehatan sekolah (UKS) yang mana terdapat pendidikan kesehatan,

pelayanan kesehatan dan lingkungan sekolah yang sehat. Namun di beberapa sekolah kurang efektif membuka pelayanan kesehatan. Maka untuk menanggulangi kebutuhan pelayanan ini, sekolah menunjuk dan melatih siswanya menjadi tenaga $\mathrm{P} 3 \mathrm{~K}$ agar mampu melakukan tindakan pertolongan pertama apabila diperlukan. Untuk itu perlu pelatihan First Aid didapatkan disekolah-sekolah.

Guna mengurangi dampat kecacatan ketika kecelakaan di lingkungan sekolah, terdapat komponen UKS yang digalakkan oleh pemerintah yakni terdapat pendidikan kesehatan, pelayanan kesehatan. Namun di beberapa sekolah kurang efektif dalam pemberian pendidikan kesehatan cara 
pertolongan pertama ketika terjadi kecelakaan dilingkungan sekolah.. Maka untuk menanggulangi kebutuhan pelayanan ini, sekolah menunjuk dan melatih siswanya menjadi tenaga $\mathrm{P} 3 \mathrm{~K}$ agar mampu melakukan tindakan pertolongan pertama apabila diperlukan. Untuk itu perlu pelatihan First Aid didapatkan disekolah-sekolah.

Tujuan dari pengabdian masyarakat ini adalah melatih siswa-siswi generasi penerus untuk mengurangi efek cedera, cacat serta kematian saat terjadi kecelakaan disekitarnya.

\section{METODE PENERAPAN}

Pengabdian ini dilaksanakan dalam bentuk pelatihan selama 2hari kepada siswa siswi SMA 2 KAMPAR. Dalam pelatihan ini menggunakan metode pelatihan yang diantaranya diawali penyuluhan materi, diskusi, serta simulasi.

\section{HASIL DAN PEMBAHASAN}

Kegiatan pengabdian kepada masyarakat ini telah dilaksanakan dengan metode pelatihan, simulasi kepada siswa/siswa di SAM 2 Kampar Kiri pada tanggal 11 Agustus 2017 dengan rincian waktu:

8.00-11.00 : Pelatihan pada siswa/siswa kelas X dan XI

13.30-15.00 : pelatihan pada siswa/siswi kelas XII

Pada saat pelatihan, Alhamdulillah animo dan interaksi dengan siswa/siswi sangat baik. Hal ini dibuktikan dengan banyaknya keinginan siswa/siswi untuk mencobakan pelaksanaan saat pelatihan berlangsung.

Pelaksanaan kegiatan mencakup beberapa komponen, diantaranga :

1. Kehadiran siswa/siwi dari awal kegiatan samapi dengan akhir

2. Pelaksanaan kegiatan pengabdian sesuai dengan waktu yang dijadwalkan

3. Penyampaian materi sesuai dengan yang direncanakan

4. Antusias para siswa sangat baik

Dari komponen diatas terlihat, sangat baiknya animo siswa dalam menerma pelatihan first aid yang dilaksanakan, pelaksanna pengabdian dengan menggunakan metode simulasi sangat baik dalam hal mentransfer ilmu, ini dibuktikan dengan banyaknya siswa/siswi yang ingin mencobakan langsung saat praktek pelaksannan first aid tersebut.

Gambar 1. 
Jurnal Pengabdian Masyarakat

vol.1 no. 1 Oktober 2017

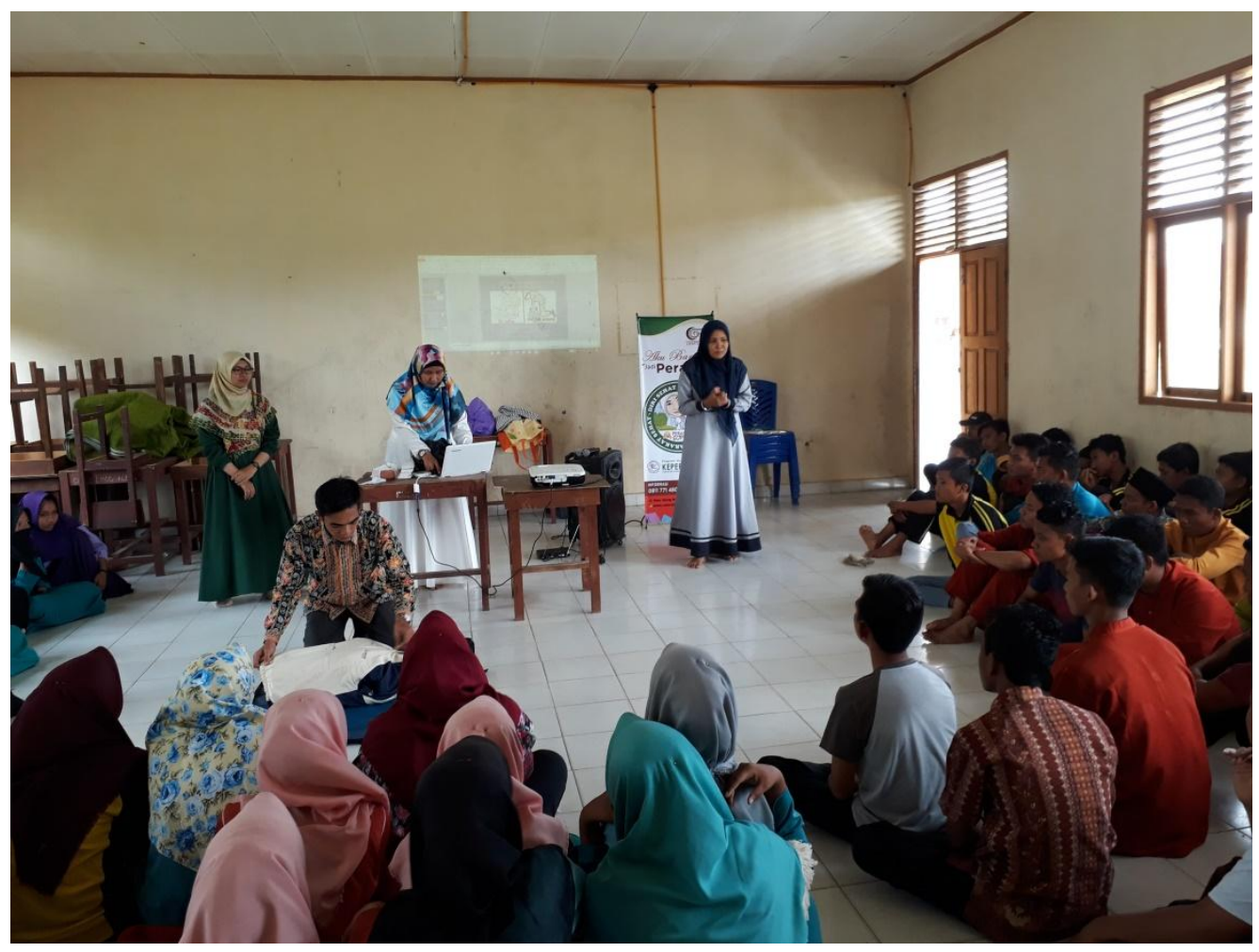

Gambar 2 
Jurnal Pengabdian Masyarakat

vol.1 no. 1 Oktober 2017

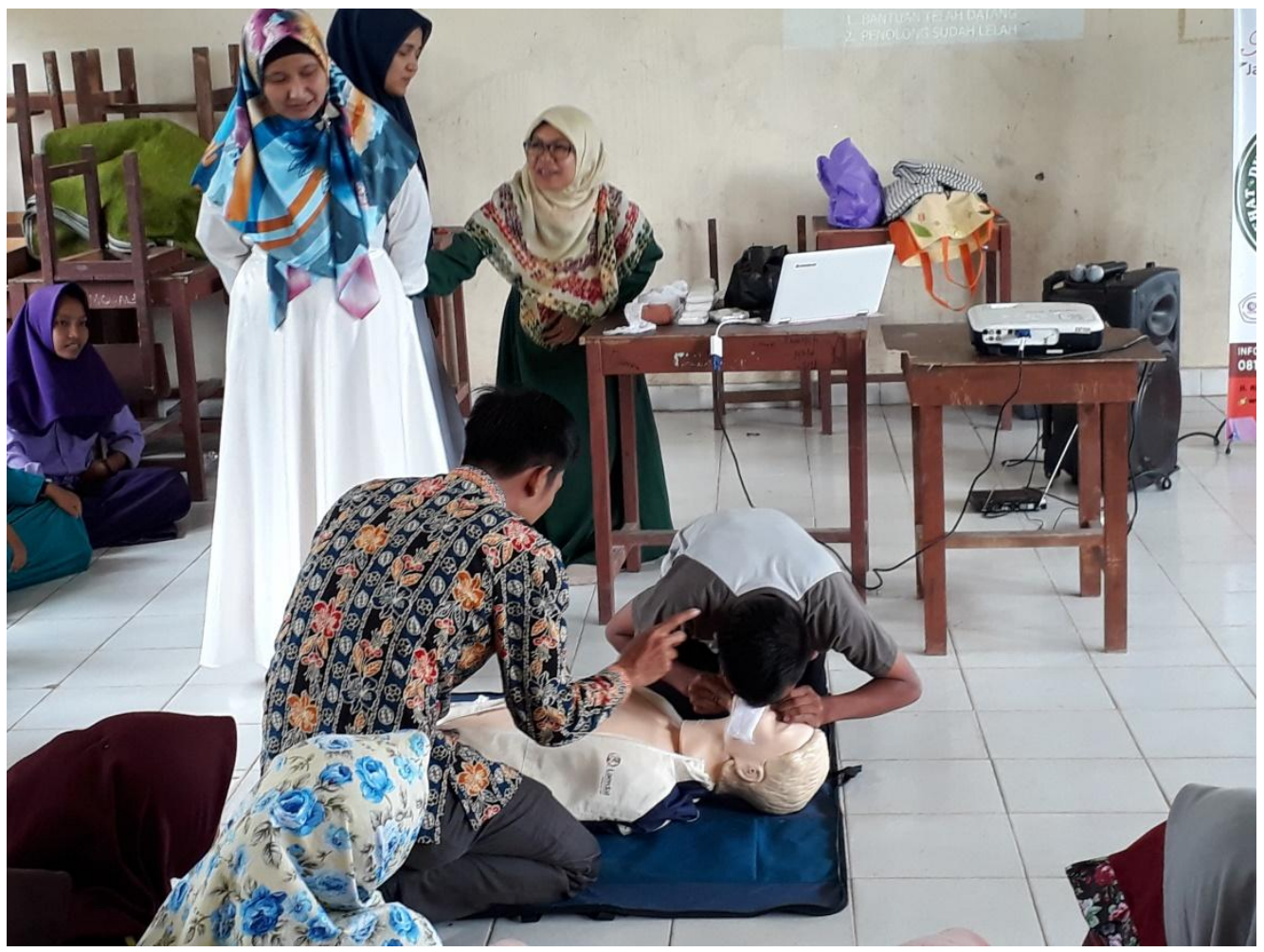

Gambar 3

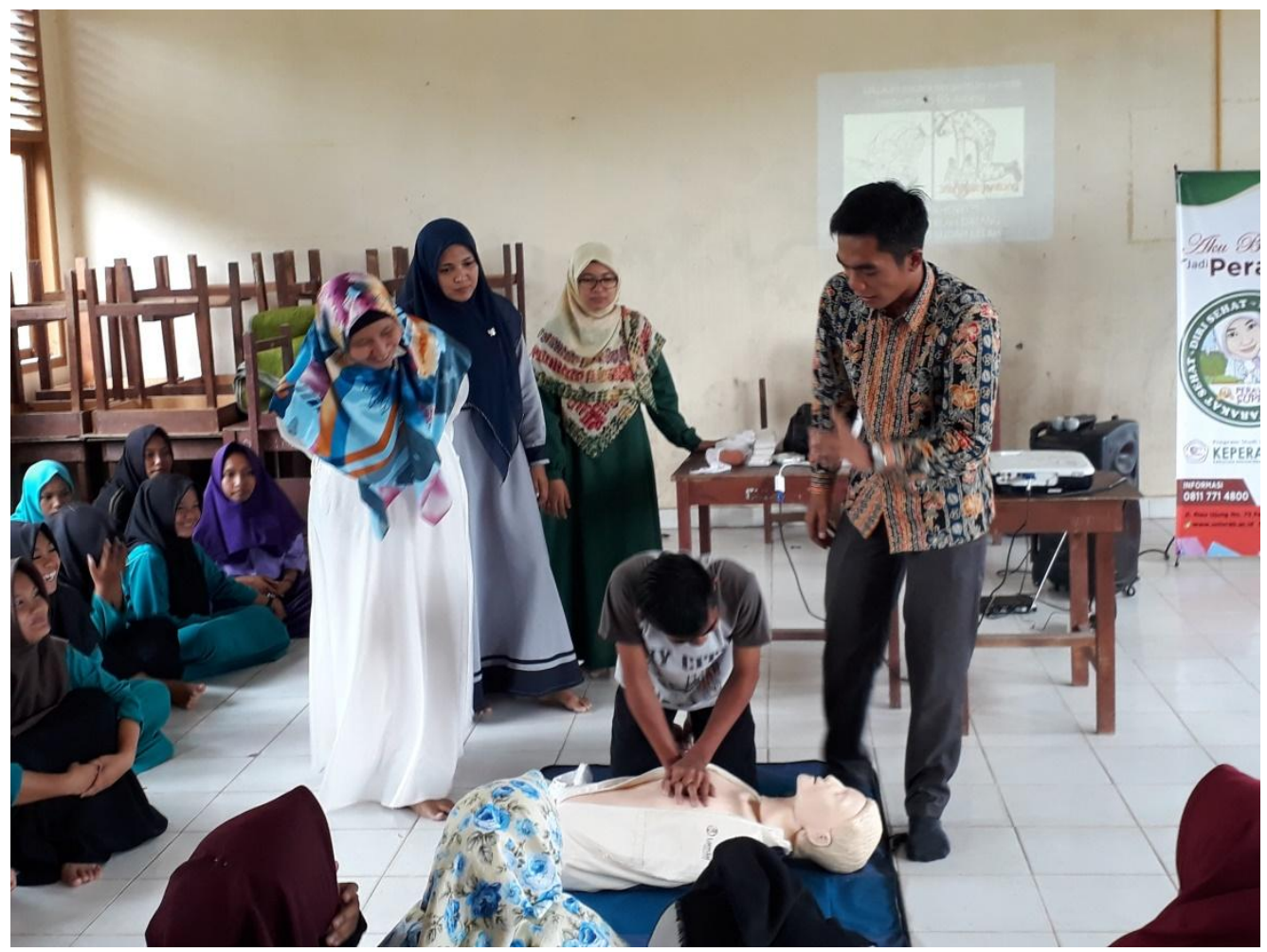


Jurnal Pengabdian Masyarakat

vol.1 no.1 Oktober 2017

Gambar 4

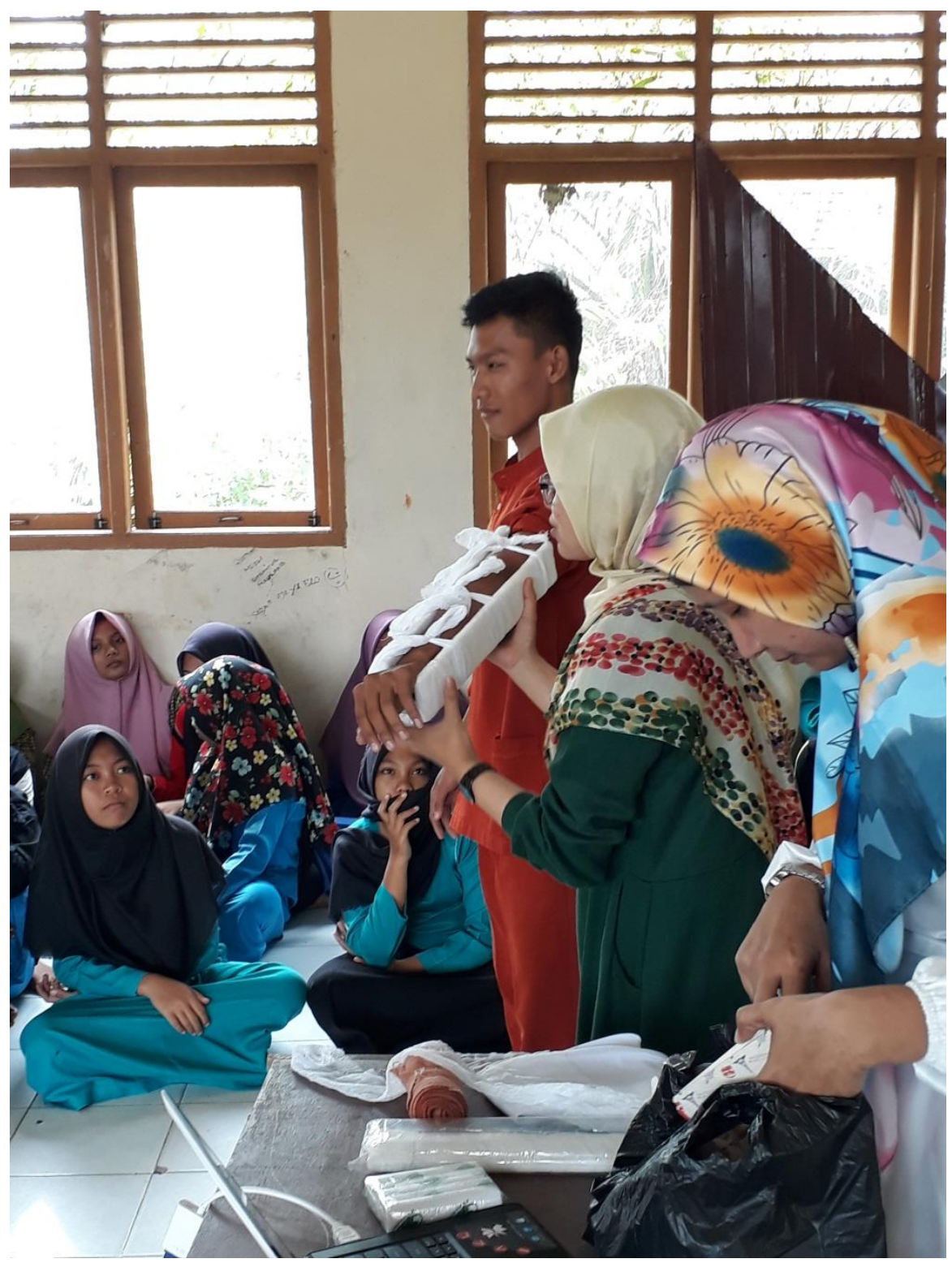

Gambar 5 
Jurnal Pengabdian Masyarakat

vol.1 no. 1 Oktober 2017

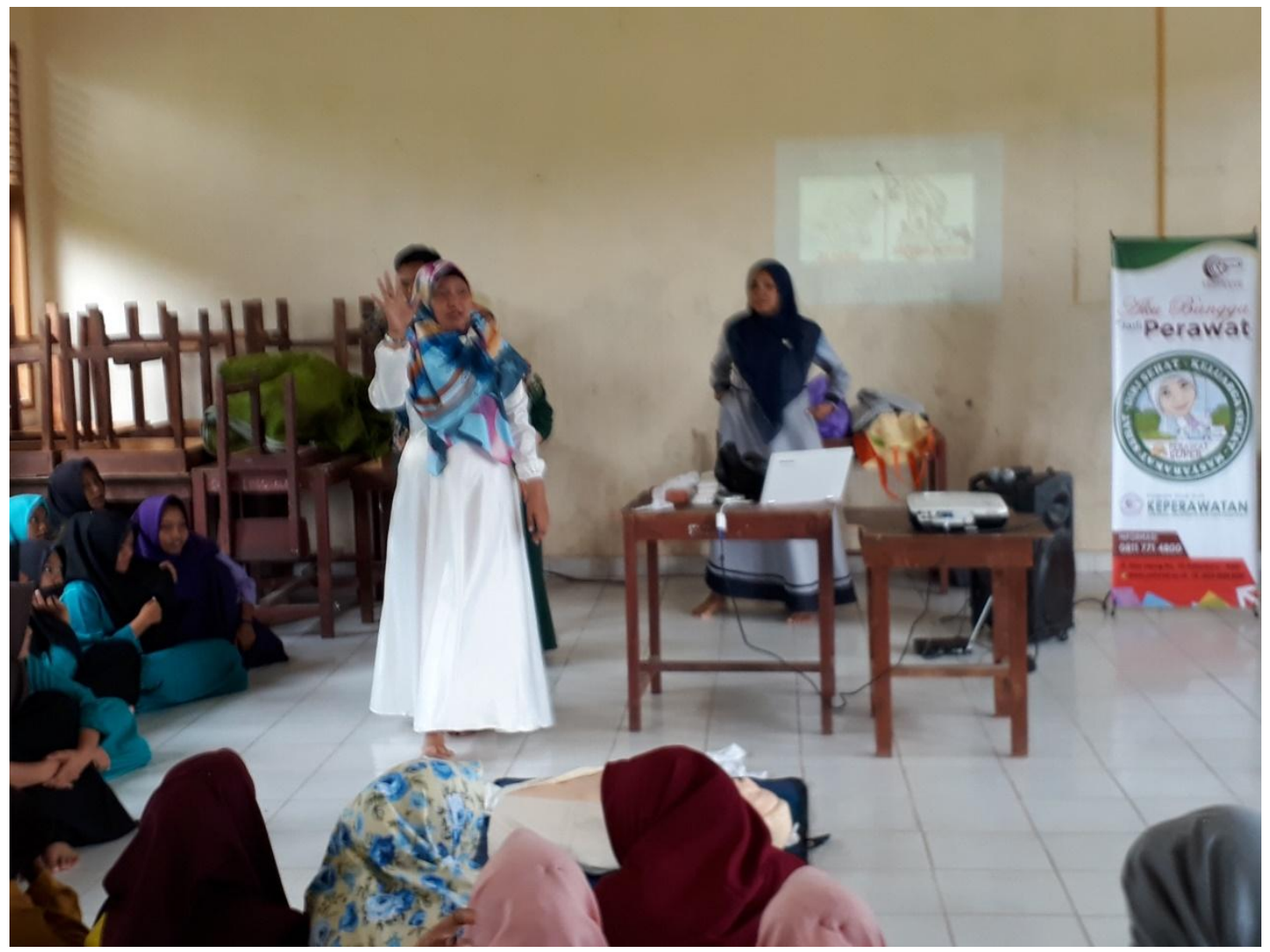

\section{Gambar 6}

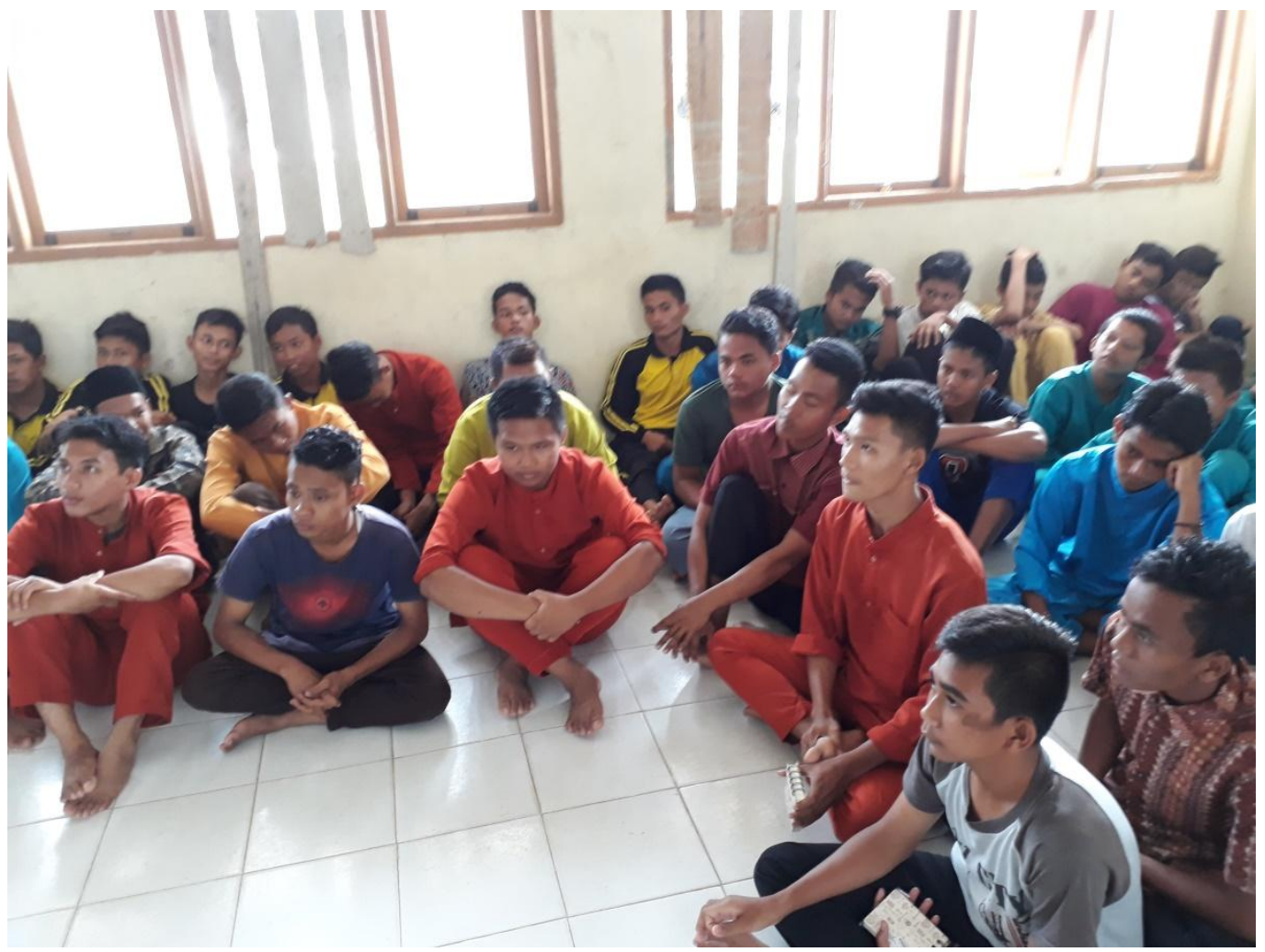

Gambar 7 
Jurnal Pengabdian Masyarakat

vol.1 no.1 Oktober 2017

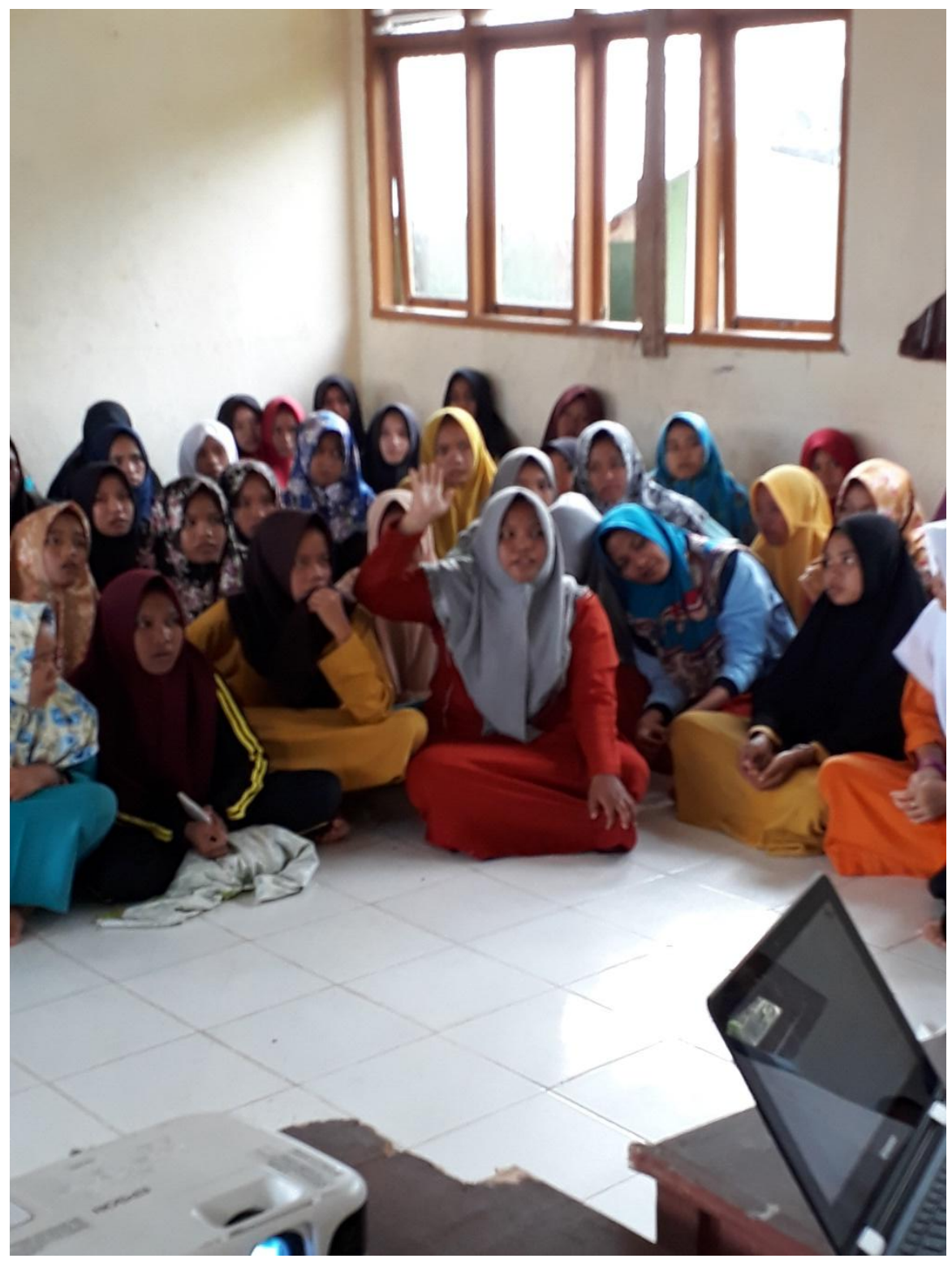

Gambar 8 
Jurnal Pengabdian Masyarakat

vol.1 no. 1 Oktober 2017

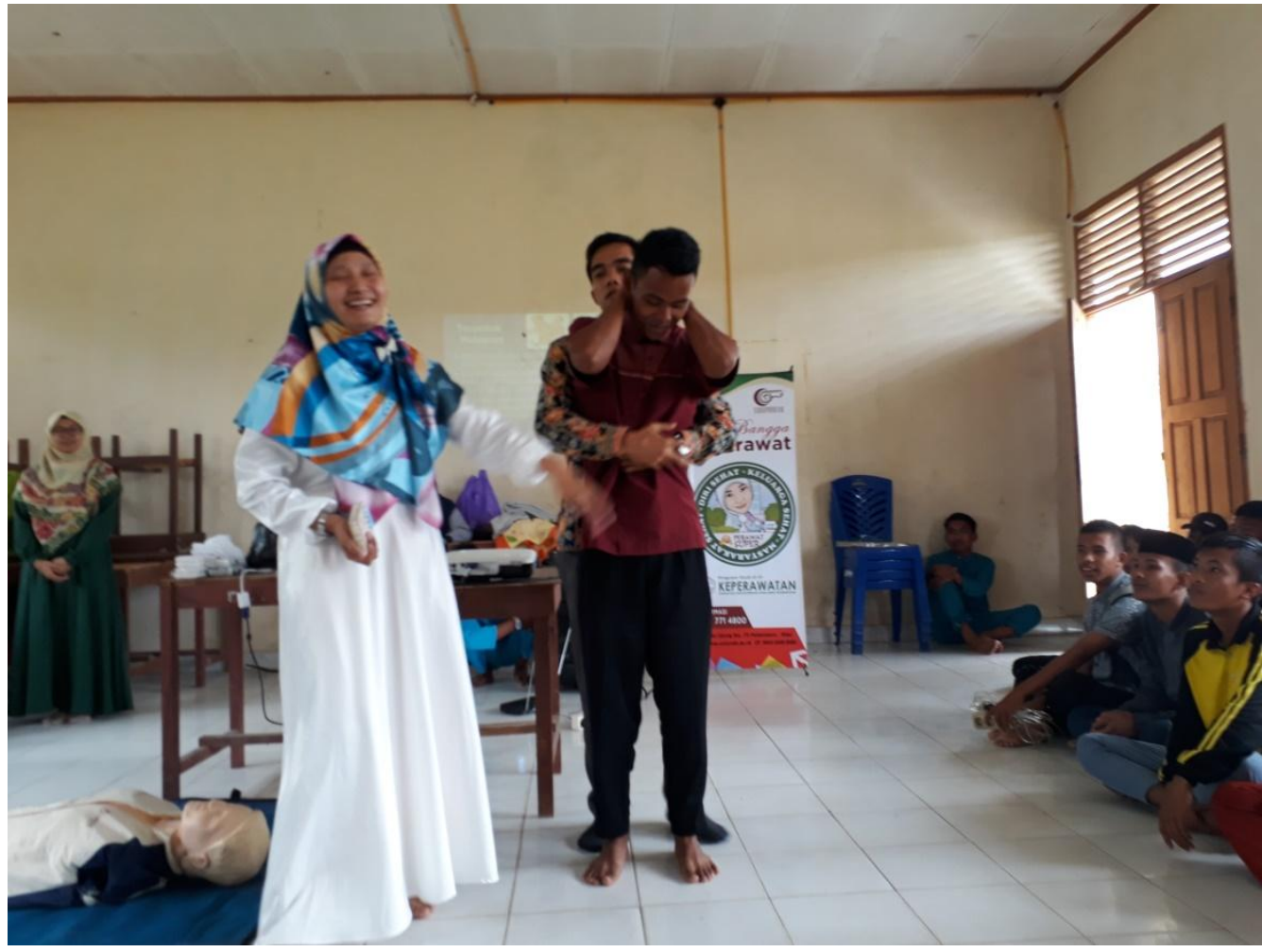

Gambar 9

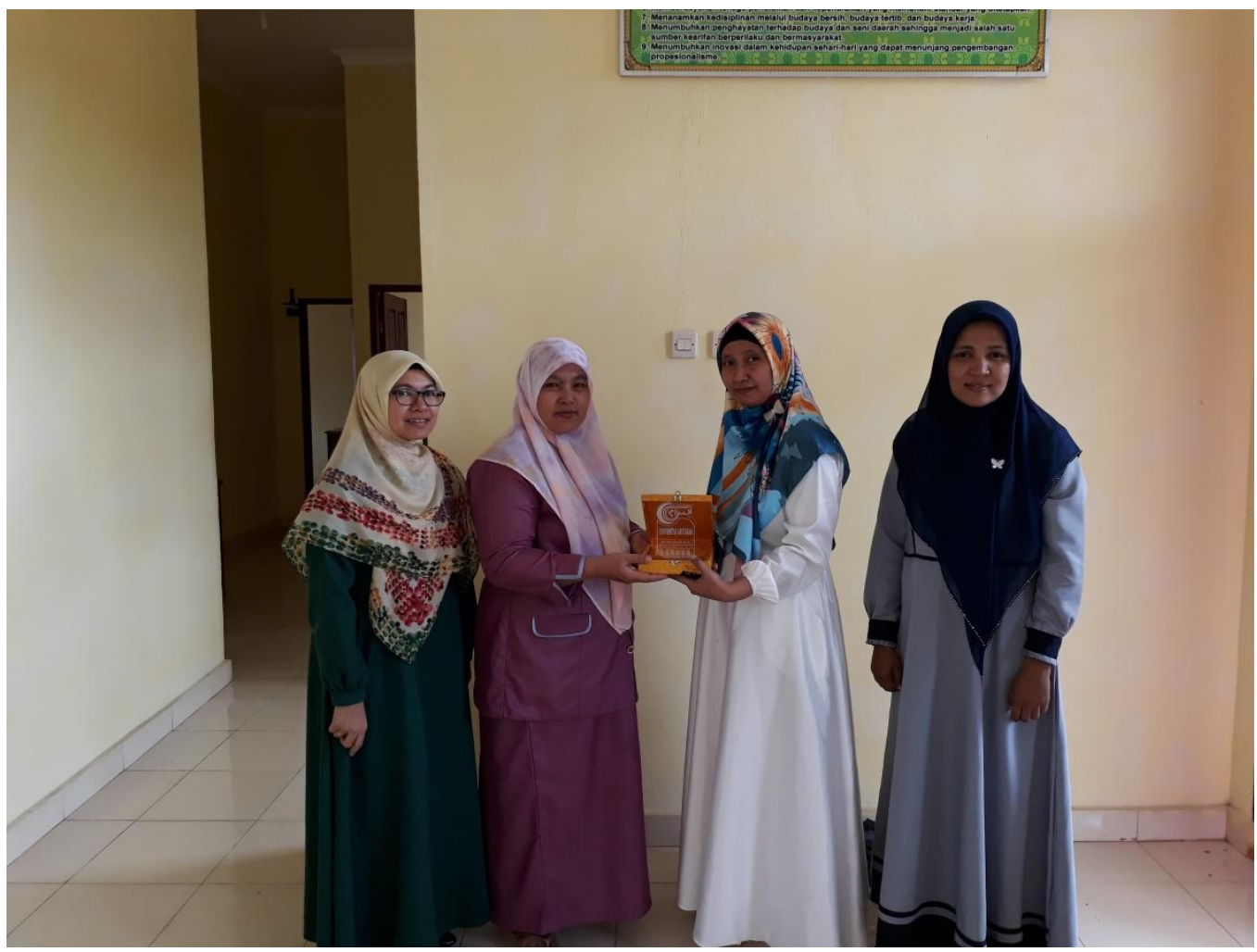

KESIMPULAN 
Kesimpulan kegiatan sosialisasi ini dilakukan selama dua sesi yakni sesi pertama untuk kelas X dan XI dan sesi ke dua untuk kelas XII serta kegiatan pelatihan berjalan baik dan lancer. Diharapkan sekolah lebih aktifberperan dalam memberikan materi first aid, yakni dengan mengaktifkan UKS disekolah serta Diharapkan kegiatan ini dapat selalu rutin dilakukan

\section{DAFTAR PUSTAKA}

1. Amin. (2013). Prinsip dan Tujuan Pertolongan Pertama pada Kecelakaan. http://www.aminudin.com/2013/02/prinsip-dan-tujuanpertolonganpertama.html

2. Andryawan, teguh prakoso. (2013). Pertolongan Pertama Pada Kecelakaan http://andryawanbisnis.files.wordpress.com/2013/04/p3k-lengkap.pdf

3. Jones \& Bartlett. (2006). Pediatric First Aid And CPR, Ed.4. Alih Bahasa Susi Purwoko. Jakarta : Arcan

4. Kemendikbud. (2012). Pedoman pelaksanan UKS Di Sekolah. Jakarta : Kementrian Pendidikan Dan Kebudayaan Direktorat Jendral Pendidikan Dasat

5. Margareta, Shinta. (2012). Buku Cerdas P3K: 101 Pertolongan Pertama Pada Kecelakaan. Yogyakarta : Niaga Swadaya

6. Murwani, Arita. (2008). Ketrampilan Dasar Praktik Klinik Keperawatan. Yogyakarta : Fitramaya

7. Musliha. (2009). Keperawatan Gawat Darurat. Jakarta: Medical book 